\title{
OPTIMUM PARAMETRIC ANALYSIS BASED ON THERMODYNAMIC MODELING OF A COMPRESSION ABSORPTION CASCADE REFRIGERATION SYSTEM
}

\author{
Naushad Ahmad Ansari ${ }^{1 *}$, Akhilesh Arora ${ }^{1}$, Samsher ${ }^{1}$, Manjunath $\mathrm{K}^{1}$
}

\begin{abstract}
In the present study a cascade refrigeration system (CRS) comprising of a vapor compression refrigeration (VCR) system in the low temperature (LT) stage and a single stage vapor absorption refrigeration (VAR) system in high temperature (HT) stage is analyzed. The scope of this work focuses on the effect of different parameters on the performance of the CRS with the help of a mathematical model. The energy and exergy analysis of the CRS is carried out with $\mathrm{CO}_{2}$ and $\mathrm{NH}_{3}$ as refrigerants in the VCR stage and the pair of $\mathrm{H}_{2} \mathrm{O}-\mathrm{LiBr}$ fluids in the VAR stage. It is observed that COP and exergetic efficiency of the CRS reduce with increase in cascade condenser temperature with $\mathrm{CO}_{2}$ as a refrigerant in VCR stage whereas with $\mathrm{NH}_{3}$ as a refrigerant in VCR stage, the COP increases with increase in cascade condenser temperature, it attains a maximum value and then decreases.
\end{abstract}

\section{Keywords: Absorption, Compression, COP, Generator, Cascade Condenser, Exergetic Efficiency}

\section{INTRODUCTION}

A cascade refrigeration system is suitable for low temperature applications in the temperature range from $-30^{\circ} \mathrm{C}$ to $-100^{\circ} \mathrm{C}$ in various industries such as pharmaceutical, food, chemical, blast freezing and liquefaction of gases. For achieving temperature below $-40^{\circ} \mathrm{C}$ by using a simple vapor compression system or a single stage absorption system is uneconomical as suggested by Chakravarthy et al. (1). The disadvantage of the VCR systems in this type of applications is their high electricity consumption. This disadvantage can be overcome by a novel cascade refrigeration system comprising of VCR system in low temperature stage and a VAR system in high temperature stage. The VAR system can be operated by waste heat assumed to be supplied in the generator of absorption section by industrial waste heat as done by Cimsit and Ozturk (2) and therefore electricity consumption can be reduced. Reddy et al (3) investigated that a natural gas-fired combined cycle power plant is better compared to a coal-fired supercritical thermal power plant from energetic and exergetic efficiency view point. Reddy et al. (4) did exergy analysis of vapor compression refrigeration system with few selected refrigerants, on comparing the performance they found that refrigerant R134a has shown better results in all respect whereas refrigerant $\mathrm{R} 407 \mathrm{C}$ has shown poor results. The energy analysis of a compression absorption cascade refrigeration system with $\mathrm{CO}_{2}$ and $\mathrm{NH}_{3}$ as refrigerants in the compression stage and the pair of $\mathrm{NH}_{3}-\mathrm{H}_{2} \mathrm{O}$ in the absorption stage was done and by Seara et al. (5) and the $\mathrm{COP}$ of compression system to be 2.602 and 2.463 with $\mathrm{CO}_{2}$ and $\mathrm{NH}_{3}$ respectively at an evaporator temperature of $-45^{\circ} \mathrm{C}$ was computed.

Cimsit and Ozturk (2) in the study using $\mathrm{H}_{2} \mathrm{O}-\mathrm{LiBr}$ and $\mathrm{NH}_{3}-\mathrm{H}_{2} \mathrm{O}$ in absorption stage and R-134A, R$410 \mathrm{~A}$ and $\mathrm{NH}_{3}$ in vapour compression stage investigated that overall $\mathrm{COP}$ of the system improves by $33 \%$ with $\mathrm{H}_{2} \mathrm{O}-\mathrm{LiBr}$, electrical energy consumption in the cascade refrigeration cycle is $48-51 \%$ lower than the conventional vapour compression cycle and also heat energy requirement reduces by $35 \%$ at generator side. Riffat and Shankland (6) did the energy analysis of various configuration of vapor absorption and integrated compression absorption systems for water-lithium bromide systems and obtained higher COP for integrated system compared to individual one. Kairouani and Nehdi (7) in a proposed cascade cycle which is powered by geothermal energy with $\mathrm{NH}_{3}-\mathrm{H}_{2} \mathrm{O}$ in absorption system and $\mathrm{R} 717, \mathrm{R} 22$ and $\mathrm{A} 134 \mathrm{~A}$ in vapour compression system reported that $\mathrm{COP}$ of cascade cycle to be $37-54 \%$ higher than the vapour compression cycle and calculated the COP as 5.5. Meng et al. (8) in their study proposed a hybrid system utilising low grade energy from solar energy to run the absorption stage saving conventional energy used $\mathrm{NH}_{3}-\mathrm{H}_{2} \mathrm{O}$ in absorption stage and $\mathrm{R} 134 \mathrm{~A}$ in vapour compression stage. Colorado and Velazquez (9) performed exergy based thermodynamic analysis of compression-absorption refrigeration cycle using $\mathrm{R} 134 \mathrm{a}, \mathrm{NH} 3$ and $\mathrm{CO} 2$ in $\mathrm{VCR}$ cycle and $\mathrm{H} 2 \mathrm{O}-\mathrm{LiBr}$ in VAR cycle to find out best working substance and suitable operating parameters. They concluded that highest irreversibility takes place in cascade condenser. Garimella et al. (10) using a computational model of a waste heat driven cascade system having H2O$\mathrm{LiBr}$ in VAR stage and $\mathrm{CO}_{2}$ in sub-critical VCR stage predicted that their novel cascade system consumes $31 \%$ less electricity compared to a conventional VCR cascade system. Seyfouri and Ameri (11) proposed a configuration 
of integrated refrigeration system of compression chiller and absorption chiller where a micro turbine is used to run the compression chiller at the low temperature stage and waste heat of micro turbine is used to run the absorption chiller thus saving the energy. Wang et al. (12) developed solar-assisted cascade refrigeration system. The system consists of electricity-driven vapour compression refrigeration system and solar-driven vapour absorption refrigeration system. They predicted that the system gives higher COP as compared with the conventional vapour compression refrigeration system. Chen et al. (13) investigated a system comprising of three sub systems namely power generation subsystem, an ammonia-water two stage absorption refrigeration subsystem and a $\mathrm{CO}_{2}$ compression refrigeration sub-system has concluded that $\mathrm{COP}$ of such two-stage absorption system is $50 \%$ higher than the conventional two stage absorption refrigeration system when the refrigeration temperature is lower than $-30^{\circ} \mathrm{C}$. Arora et al. (14) predicted that optimum solution distribution ratio was same for maximum COP and maximum exergetic efficiency for a double effect parallel flow absorption system with $\mathrm{LiBr}-\mathrm{H}_{2} \mathrm{O}$ as working pair of fluid. Kutlu, et al. (15) theoretically analyzed a two-phase ejector refrigeration system with bi-evaporator refrigeration and predicted the COP improvement up-to 21\% in Mediterranean climate region. Dixit et al. (16) did the analysis on a triple effect refrigeration cycle which was waste driven and consisted of an ejector organic Rankine cycle, vapor absorption cycle and vapor compression cycle and computed the energy efficiency to be $21.79 \%$ while exergetic efficiency to be around $12.91 \%$. Arora et al. (17) carried out the thermodynamic analysis of a water/lithium-Bromide based half effect absorption refrigeration system and predicted a same optimum intermediate pressure for maximum $\mathrm{COP}$ and maximum exergetic efficiency for the system while further, predicting maximum COP range to be $0.415-0.438$ and maximum exergetic efficiency range to be $6.96-13.74 \%$. Jain et al. (18) did the optimisation with combination of R410a as a refrigerant in VCR stage and aqua Li-Br solution in VAR stage in similar cascade refrigeration system where non-linear programming has been used to optimize the system. Jain et al. (19) did thermodynamic study of similar cascade refrigeration system using water and $\mathrm{Li}-\mathrm{Br}$ solution in VAS stage and R22, R 410A, R 407C and R134A in VCR stage, while comparing their performances accordingly found that R134a as a suitable refrigerant. Jain et al. (20) did the multi-objective optimization using NSGA-II technique on the performance of a $170 \mathrm{~kW}$ vapour-absorption cascade refrigeration system and concluded that multi-objective design criteria is better than two single-objective thermodynamic and total product cost optimized designs. Dixit et al. (21) carried a study on similar cascade refrigeration cycle with $\mathrm{CO}_{2}, \mathrm{NH}_{3}$ and $\mathrm{R}-134 \mathrm{a}$ in compression stage and $\mathrm{H}_{2} \mathrm{O}-\mathrm{LiBr}$ in absorption stage predicted that combination of $\mathrm{R}-$ 134a with $\mathrm{H}_{2} \mathrm{O}-\mathrm{LiBr}$ is most suitable of the three combinations based on comparing operational parameters of such a system. Kaushik et al. (22) studied a similar system and predicted the optimum generator temperature for maximum COP to be $83.5^{\circ} \mathrm{C}$ and for maximum exergetic efficiency to be $72.25^{\circ} \mathrm{C}$ with ammonia as a refrigerant in the low temperature cycle.

Megdouli et al (23) analyzed a hybrid vapor compression refrigeration (HVCR) system, which combines a vapor compression refrigeration (VCR) system and an ejector refrigeration (ER) system. Thermodynamic investigations using $\mathrm{CO} 2$ as a refrigerant, were performed with energetic and exergetic methods, and the comparative analyses with the VCR system were conducted. The results indicated that for the same cooling capacity, the coefficient of performance (COP) of the HVCR system showed 25\% higher COP and the total mechanical power consumption was reduced by $20 \%$ than that of conventional VCR system, respectively. Patel et al (24) in their study on cascaded vapor compression-absorption system powered by solar-biomass organic Rankine cycle with working fluid Toluene and R245fa proposed and analyzed that Thermo-economic performance of the system is influenced by the type of working fluid of organic Rankine cycle, electricity and heating cost, biomass type, discount rate, solar collector field and location of installation. Chen et al (25) proposed and analyzed a novel heat driven absorption compression system to reach a temperature as low as $-60^{\circ} \mathrm{C}$. The proposed system had three sub-systems namely a power cycle, an ammonia water absorption cycle and a $\mathrm{CO} 2$ vapor compression refrigeration cycle. They concluded that the results predicted were adaptable and suitable for practical applications. Yingjie Xu et al (26) proposed a low-grade heat driven cascade system named as ejection-compression refrigeration system and predicted that the proposed system with low electricity consumption had higher COP compared to a conventional vapor compression system and conventional ejector compression refrigeration system. Yingjie Xu et al (27) studied and compared two low grade heat driven compression-absorption cycles. Their study was based on energy, exergy, environmental and economic. They compared a novel absorption-compression cycle with evaporator sub-cooler and a conventional absorption-compression cycle with an evaporator-condenser. They predicted that novel absorption-compression system was more economical when waste heat was used whereas the conventional absorption-compression system was more economical when solar heat was used. 
This paper seeks to remedy the highlighted gap of knowledge in the field of the study by conducting the thermodynamic analysis based on energy and exergy analysis to achieve a compromise between the optimum generator temperature, cascade condenser temperature, cascade approach and other variables at which maximum $\mathrm{COP}$ and maximum energetic efficiency occurs. Thus, it could be possible to formulate the theoretical framework of the procedures for energy saving and optimization which is environment friendly.

\section{DESCRIPTION OF THE COMPRESSION ABSORPTION CASCADE REFRIGERATION SYSTEM}

The compression-absorption cascade system which is being considered is shown schematically in Figure1(a). It consists of a single stage compression system in the low temperature stage and a single effect absorption system in the high temperature stage. The compression system comprises of the evaporator, compressor, condenser and an expansion device. The absorption system uses the pair water-lithium bromide and its major components are the absorber, generator, condenser, evaporator, solution heat exchanger, pump, solution throttle valve and a refrigerant throttle valve. Both systems share a common heat exchanger (cascade condenser), which operates simultaneously as the condenser of the compression system and as the evaporator of the absorption system. The compression system is used for the generation of the cooling at low temperature and the absorption system rejects heat to the surroundings, as shown in Figure1(a). This refrigeration system would decrease the electricity consumption compared to the two stages compression systems, since it is only required to operate the compression system at the low stage; meanwhile the absorption system is driven by heat.

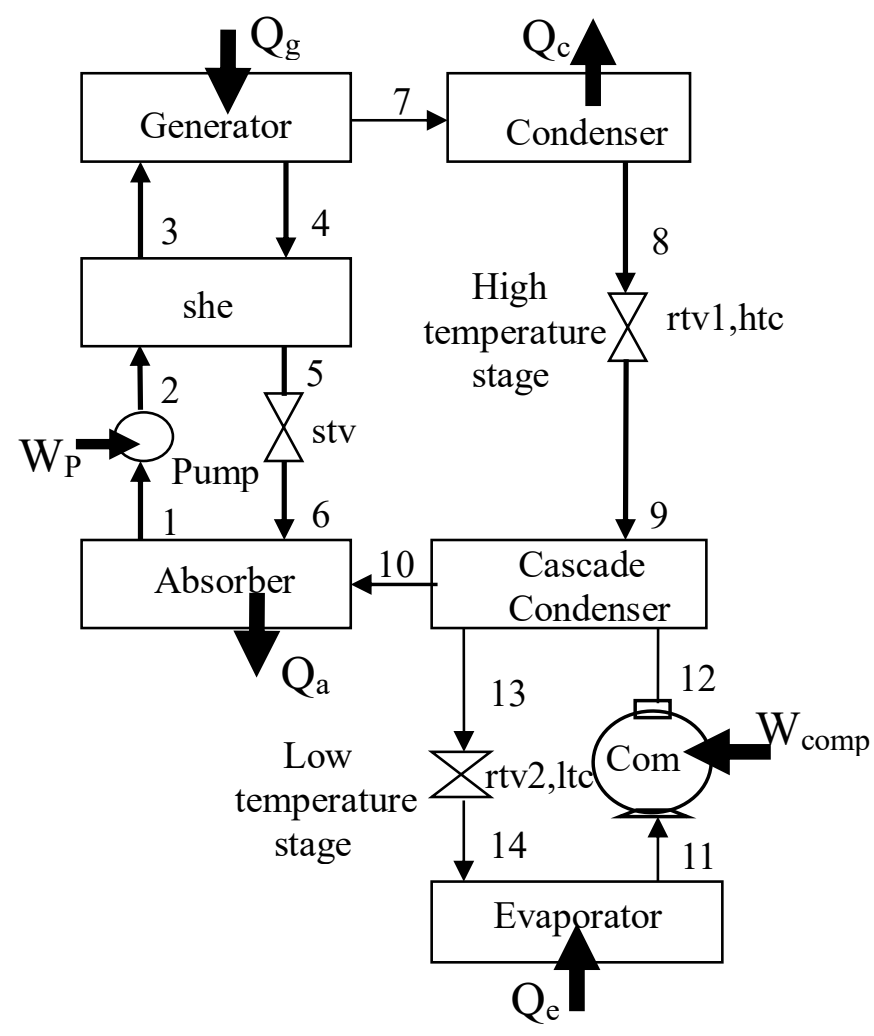

Figure 1(a). Schematic diagram of compression-absorption cascade refrigeration system

Where, $\mathrm{Q}_{\mathrm{a}}=$ heat rejected from absorber, $\mathrm{W}_{\mathrm{p}}=$ pump work, $\mathrm{Q}_{\mathrm{g}}=$ heat generated in generator, $\mathrm{Q}_{\mathrm{c}}=$ heat rejected from condenser, $\mathrm{W}_{\text {comp }}=$ compressor work, $\mathrm{Q}_{\mathrm{e}}=$ heat absorbed in evaporator, $\mathrm{stv}=$ solution thermostatic expansion valve, $\mathrm{rtv} 1=$ refrigerant thermostatic expansion valve in htc, htc $=$ high temperature circuit, rtv2= refrigerant thermostatic expansion valve in $1 t c, 1 t c=$ low temperature circuit, $s h e=$ solution heat exchanger. 


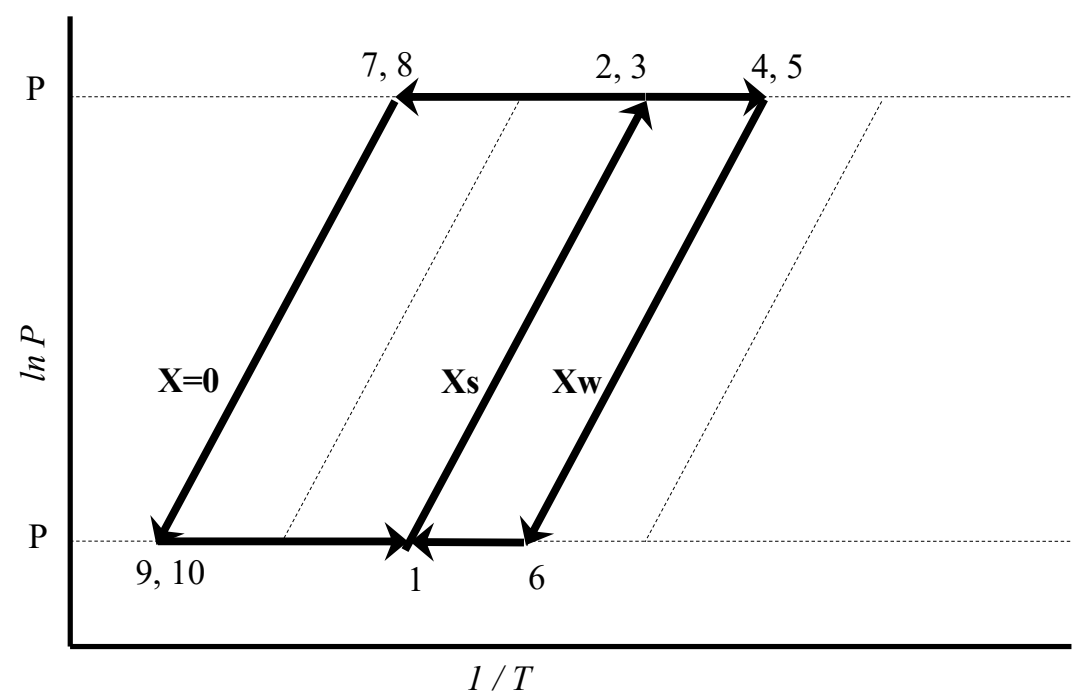

Figure 1(b). In P-1/T diagram for water lithium bromide Single Effect Generation VAR system

\section{THERMODYNAMIC ANALYSIS OF THE COMPRESSION ABSORPTION CASCADE REFRIGERATION SYSTEM}

The thermodynamic analysis of compression absorption system involves the principles of mass conservation, energy conservation and exergy balance.

\section{Mass Balance}

The mass flow rate of refrigerant through each component of low temperature circuit is $\dot{m}_{r_{-} v c r}(\mathrm{~kg} / \mathrm{s})$. It is calculated using equation (1).

$$
\dot{Q}_{e}=\dot{m}_{r_{-} v c r}\left(h_{11}-h_{14}\right)
$$

Where, $\dot{Q}_{e}$ is heat absorbed in evaporator $(\mathrm{kW})$ and $\mathrm{h}$ is enthalpy $(\mathrm{kW} / \mathrm{kg})$

Mass balance equations in high temperature circuit are specified below.

Mass balance at absorber or generator

$$
\dot{m}_{s}=\dot{m}_{r}+\dot{m}_{w}
$$

Where, $\dot{m}_{s}$ is the mass of solution $(\mathrm{kg} / \mathrm{s})$ flowing through absorber and generator.

$\dot{m}_{r}$ is the mass flow rate $(\mathrm{kg} / \mathrm{s})$ through condenser and cascade condenser.

$\dot{m}_{w}$ is the mass $(\mathrm{kg} / \mathrm{s})$ of absorbent flowing through solution heat exchanger.

\section{Energy Balance}

The energy balance equations for the system shown in Figure 1(a) are given below:

Energy balance in high temperature stage

$$
\begin{gathered}
\dot{Q}_{a}=\dot{m}_{r} h_{10}+\dot{m}_{w} h_{6}-\dot{m}_{s} h_{1} \\
\dot{Q}_{g}=\dot{m}_{r} h_{7}+\dot{m}_{w} h_{4}-\dot{m}_{s} h_{3} \\
\dot{Q}_{c}=\dot{m}_{r}\left(h_{7}-h_{8}\right) \\
\dot{Q}_{s h e}=\dot{m}_{s}\left(h_{3}-h_{2}\right)=\dot{m}_{w}\left(h_{4}-h_{5}\right) \\
\dot{W}_{p}=\dot{m}_{s}\left(h_{2}-h_{1}\right)
\end{gathered}
$$


Energy balance in low temperature stage

$$
\begin{gathered}
\dot{W}_{\text {comp }}=\dot{m}_{r_{-} v c r}\left(h_{12}-h_{1_{1}}\right) \\
\dot{Q}_{e}=\dot{m}_{r_{-} v c r}\left(h_{11}-h_{14}\right) \\
\text { Power input }=\dot{W}_{\text {comp }}+\dot{W}_{p}
\end{gathered}
$$

Energy input

$$
\dot{E}_{\text {in }}=\dot{Q}_{g}+\dot{Q}_{e}+\dot{W}_{p}+\dot{W}_{\text {comp }}
$$

Energy output

$$
\dot{E}_{\text {out }}=\dot{Q}_{a}+\dot{Q}_{c}
$$

Coefficient of Performance (COP)

$$
C O P=\frac{\dot{Q}_{e}}{Q_{g}+\dot{W}_{p}+\dot{W}_{c o m p}}
$$

\section{Exergy Balance}

Exergy destruction in components of the cascade system is furnished below: Exergy analysis in high temperature stage

$$
\begin{aligned}
& \dot{E D_{a}}=\dot{m}_{r}\left(h_{10}-T_{o} s_{10}\right)+\dot{m}_{w}\left(h_{6}-T_{o} s_{6}\right)-\dot{m}_{s}\left(h_{1}-T_{o} s_{1}\right) \\
& \dot{E D_{g}}=\dot{m}_{s}\left(h_{3}-T_{o} s_{3}\right)-\dot{m}_{w}\left(h_{4}-T_{o} s_{4}\right)-\dot{m}_{r}\left(h_{7}-T_{o} s_{7}\right)+\dot{Q}_{g}\left(1-\frac{T_{0}}{T g}\right) \\
& \dot{E D_{c}}=\dot{m}_{r}\left(\left(h_{7}-h_{8}\right)-T_{o}\left(s_{7}-s_{8}\right)\right) \\
& \dot{E D_{c c}}=\dot{m}_{r}\left(\left(h_{9}-h_{10}\right)-T_{o}\left(s_{9}-s_{10}\right)\right)+\dot{m}_{r_{-} v c r}\left(\left(h_{12}-h_{13}\right)-T_{o}\left(s_{12}-s_{13}\right)\right) \\
& \dot{E} \dot{D}_{\text {she }}=\dot{m}_{s}\left(\left(h_{2}-h_{3}\right)-T_{o}\left(s_{2}-s_{3}\right)\right)+\dot{m}_{w}\left(\left(h_{4}-h_{5}\right)-T_{o}\left(s_{4}-s_{5}\right)\right) \\
& \dot{E D_{r t v_{-} h t c}}=\dot{m}_{r} T_{o}\left(s_{9}-s_{8}\right) \\
& \dot{E D_{s t v}}=\dot{m}_{w} T_{o}\left(s_{6}-s_{5}\right)
\end{aligned}
$$

Exergy analysis in low temperature stage

$$
\begin{aligned}
& \dot{E D}_{\text {comp }}=\dot{m}_{r_{-} v c r} T_{0}\left(s_{12}-s_{11}\right) \\
& \dot{E D_{e}}=\dot{m}_{r_{-} v c r}\left(h_{14}-T_{0} s_{14}\right)+\dot{Q}_{e}\left(1-\frac{T_{0}}{T_{r}}\right)-\dot{m}_{r_{-} v c r}\left(h_{11}-T_{0} s_{11}\right) \\
& \dot{E D_{r t v_{-} l t c}}=\dot{m}_{r_{-} v c r}\left(h_{13}-T_{0} s_{13}\right)--\dot{m}_{r_{-} v c r}\left(h_{14}-T_{0} s_{14}\right)=\dot{m}_{r_{-} v c r} T_{0}\left(s_{14}-s_{13}\right)
\end{aligned}
$$




$$
\begin{aligned}
\dot{E} D_{\text {total }}=\dot{E} D_{a}+\dot{E} D_{g}+\dot{E} D_{c}+\dot{E} D_{c c}+\dot{E} D_{s h e}+\dot{E} D_{r t v_{-} h t c}+\dot{E} D_{s t v}+\dot{E} D_{r t v_{-} l t c} \\
+\dot{E} D_{c o m p}+\dot{E} D_{e}
\end{aligned}
$$

\section{Exergetic Efficiency}

$$
\begin{gathered}
\eta_{e_{x}}=\frac{\text { Exergy in product }}{\text { Exergy of fuel }}=\frac{\dot{E P}}{\dot{E F}}=\frac{\dot{E F-\dot{E} D_{\text {total }}}}{\dot{E F}}=1-\frac{\dot{E D_{\text {total }}}}{\dot{E F}} \\
\dot{E F}=\dot{W}_{\text {comp }}+\dot{W}_{p}+\dot{Q}_{g}\left(1-\frac{T_{0}}{T g}\right) \\
\dot{E P}=\dot{Q}_{e}\left|\left(1-\frac{T_{0}}{T_{r}}\right)\right| \\
\eta_{e_{x}}=\frac{\dot{Q}_{e}\left|\left(1-\frac{T_{0}}{T_{r}}\right)\right|}{\dot{W}_{\text {comp }}+\dot{W}_{p}+\dot{Q}_{g}\left(1-\frac{T_{0}}{T g}\right)}
\end{gathered}
$$

\begin{tabular}{|c|c|c|c|c|}
\hline Parameters & Present Model & $\begin{array}{c}\text { Cimsit and } \\
\text { Ozturk (2012) }\end{array}$ & $\begin{array}{c}\text { Difference } \\
\%\end{array}$ & $\begin{array}{c}\text { Operating } \\
\text { Parameters }\end{array}$ \\
\hline$\dot{Q}_{a}(\mathrm{~kW})$ & 72.76 & 73.15 & 0.53 & $T_{c}=40^{\circ} \mathrm{C}$ \\
\hline$\dot{Q}_{g}(\mathrm{~kW})$ & 76.81 & 76.45 & 0.47 & $T_{g}=90^{\circ} \mathrm{C}$ \\
\hline$\dot{Q}_{c}(\mathrm{~kW})$ & 61.17 & 61.06 & 0.1 & $T_{c c}=10^{\circ} \mathrm{C}$ \\
\hline$\dot{W}_{\text {СOMP }}(\mathrm{kW})$ & 7.83 & 8.08 & -3.09 & $T_{e_{-} v c r}=-10^{0} \mathrm{C}$ \\
\hline$C O P$ & 0.594 & 0.592 & 0.34 & $\begin{array}{c}\epsilon_{\text {she }}=0.60 \\
\eta_{\text {comp }}=72 \%\end{array}$ \\
\hline & & & & $\dot{Q}_{e}=50(\mathrm{~kW})$ \\
\hline
\end{tabular}

\section{Model validation}

The present work has been validated with the Cimsit and Ozturk (2) investigation with $\mathrm{LiBr}-\mathrm{H}_{2} \mathrm{O}$ and $\mathrm{NH}_{3}$ as working fluids in VAR cycle and VCR cycle respectively. The difference between the present data and predicted by Cimsit and Ozturk (2) in Table 1 falls within the accepted range.

Table 1. Result validation

Thermodynamic modeling of a similar system done by Kaushik et al. (22) predicted the optimum generator temperature for maximum COP to be $83.5^{\circ} \mathrm{C}$ and maximum exergetic efficiency to be $72.25^{\circ} \mathrm{C}$ with ammonia as fluid in low temperature stage which can be validated for the same as calculated in the present study to be $84.21^{\circ} \mathrm{C}$ and $72.59^{\circ} \mathrm{C}$ respectively. The error may be due to approximation but in agreement could be accepted. Similarly, at higher absorber and condenser temperature $\left(40^{\circ} \mathrm{C}\right)$ and other same parameters Dixit et al. (21) investigated cascade condenser temperature to be $12.47^{\circ} \mathrm{C}$ and $8.64^{\circ} \mathrm{C}$ for maximum COP for ammonia and carbon dioxide respectively. In the present study the same has been computed as $13^{\circ} \mathrm{C}$ and $9{ }^{\circ} \mathrm{C}$ for ammonia and carbon dioxide respectively. The error may be due to approximation and could be agreed upon. 


\section{RESULTS AND DISCUSSION}

The present analysis has been done considering two different natural refrigerants, carbon dioxide and ammonia in the compression system. The absorption system uses the water-lithium bromide pair. A simple steady state simulation model based on sequential modular approach has been developed and implemented in a computer program using EES software taken from Klein and Alvarado (28). The model equations are formulated from species, mass, energy and exergy balances. State equations used for the carbon-dioxide and ammonia at equilibrium and the thermodynamic properties are taken from built-in functions in EES. The properties of waterlithium bromide solution are taken from Pa'tek and Klomfar (29). The parameters assumed for computation of results are mentioned below:

1. Cooling capacity $\left(\dot{Q}_{e}\right)$

2. Isentropic efficiency of compressor, $\left(\eta_{\text {comp }}\right)$

3. Evaporator temperature, $\left(T_{e_{-} v c r}\right)$

4. Cascade Condenser temperature, $\left(T_{c c}\right)$

5. Generator temperature $\left(T_{g}\right)$

6. Absorber temperature $\left(T_{a}\right)$

7. Effectiveness of solution heat exchanger, $\left(\epsilon_{\text {she }}\right)$

8. Condenser temperature $\left(T_{c}\right)$

9. Approach in cascade condenser (A)

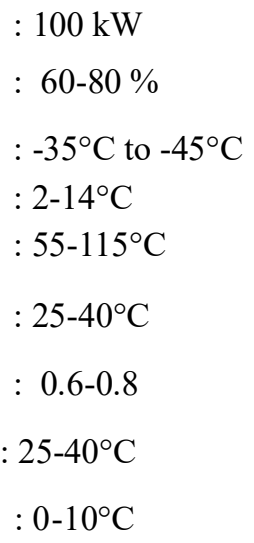

The cascade condenser temperature is assumed to vary between $2-14^{\circ} \mathrm{C}$ because the lowest temperature in water lithium bromide system depends upon the freezing point of water and which can't be below $0^{\circ} \mathrm{C}$.

\section{Effect of Cascade Condenser Temperature on COP and Exergetic Efficiency}

Since the selection of cascade condenser temperature depends upon the freezing point of refrigerant (water), hence for a given set of parameters viz. evaporator temperature (depends upon application), condenser and absorber temperatures (depends upon ambient conditions) there must exist a unique generator temperature corresponding to which COP is maximum. Similar to this, the exergetic efficiency will be maximum corresponding to some other value of generator temperature. This point is highlighted in Figure 2 for ammonia and carbon dioxide cascade systems. It can be observed that maximum COP and maximum exergetic efficiency occur corresponding to different generator temperatures. The maximum COP occurs corresponding to generator temperature of $84.21^{\circ} \mathrm{C}$ and maximum exergetic efficiency occurs corresponding to $72.59^{\circ} \mathrm{C}$ for both the refrigerants. It may be predicted that under similar condition of the cycle the optimum generator temperature remains same irrespective of the refrigerants in low temperature stage.

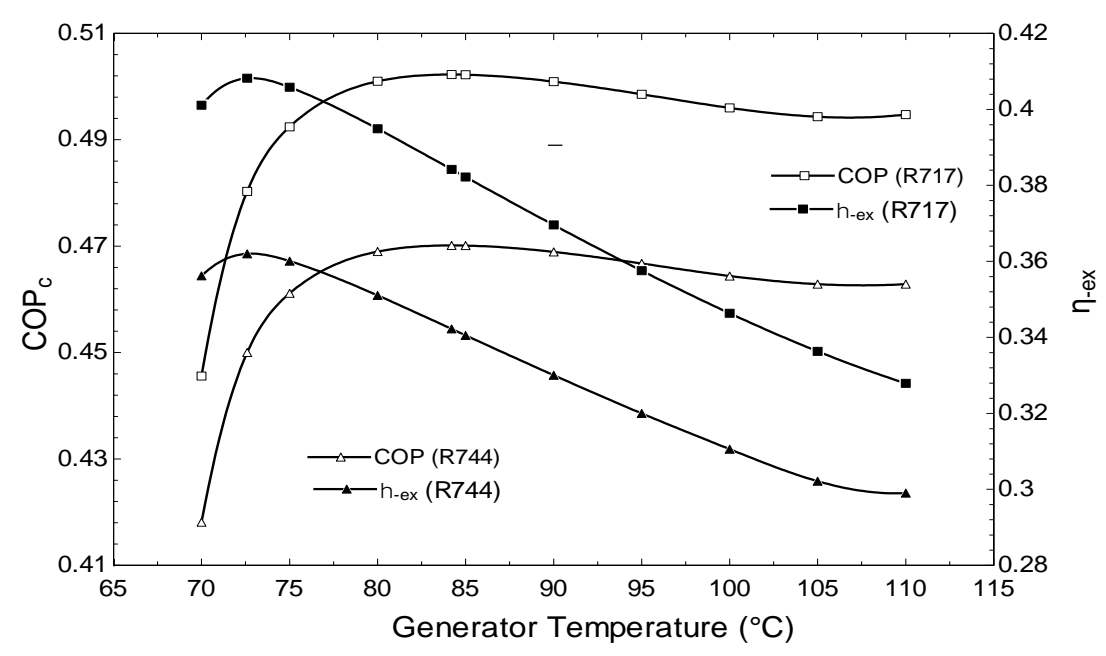

Figure 2. Variation of $\mathrm{COP}$ and $\eta \_$ex versus generator temperature for ammonia "R717" and carbon-dioxide "R744" $\left(\mathrm{Ta}=\mathrm{Tc}=35^{\circ} \mathrm{C}, \mathrm{Te} \_\mathrm{vcr}=-40^{\circ} \mathrm{C}, \varepsilon_{-}\right.$she $=0.75, \eta_{\_}$comp $\left.=0.8, \mathrm{Qe} \_\mathrm{vcr}=100 \mathrm{~kW}, \mathrm{~A}=0^{\circ} \mathrm{C}, \mathrm{To}=298.15 \mathrm{~K}\right)$ 


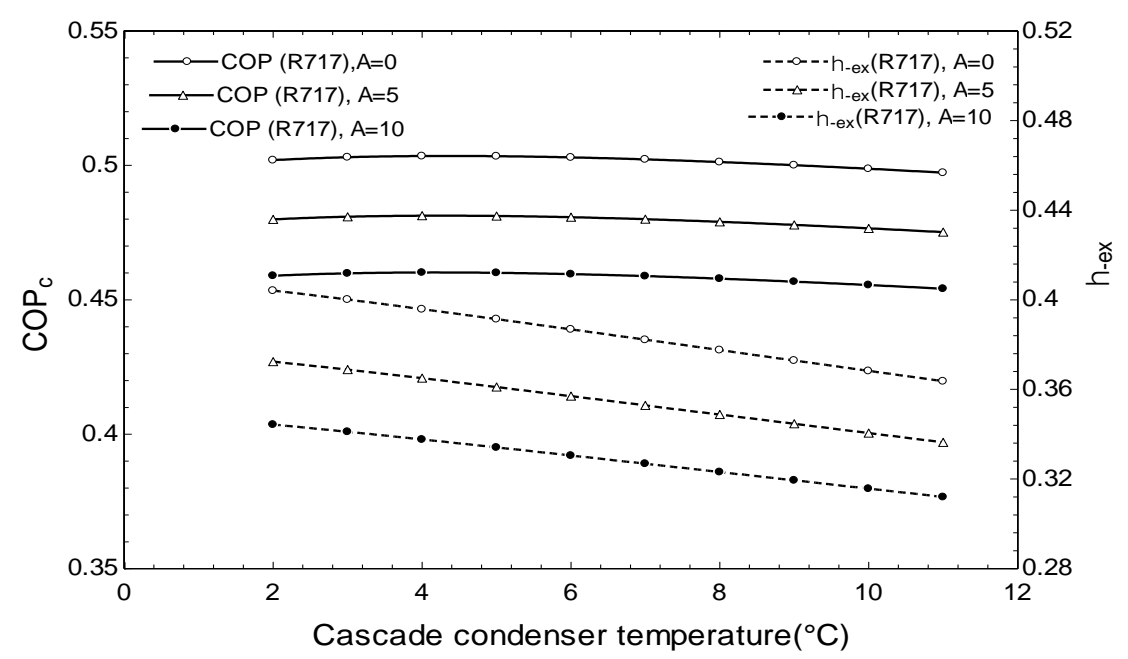

(a)

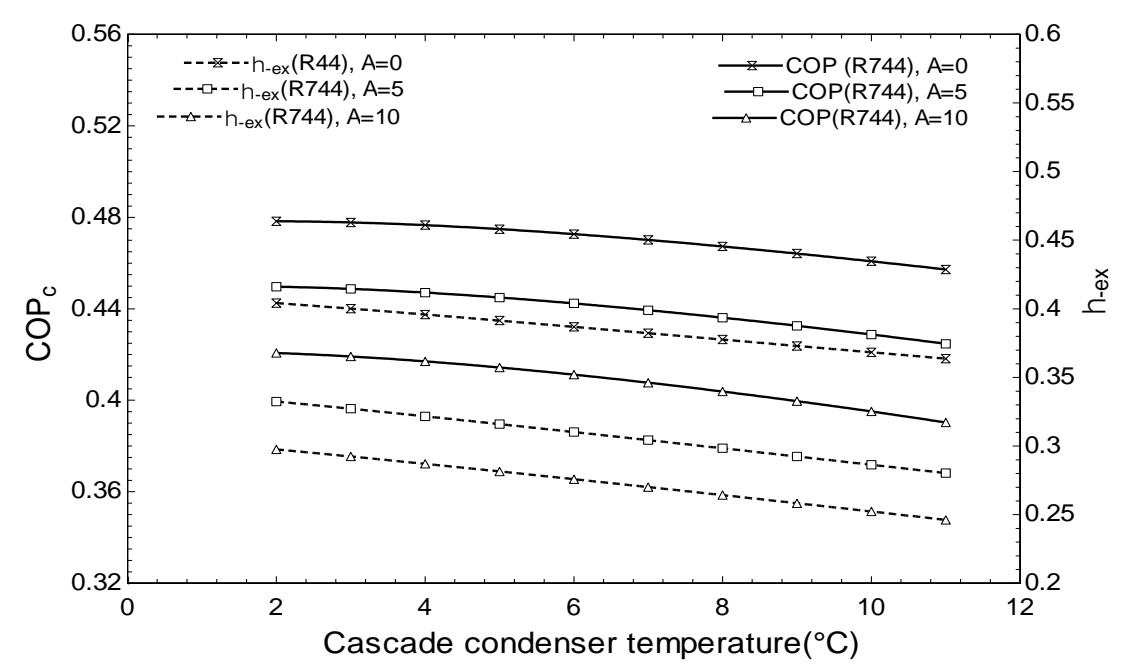

(b)

Figure 3. Effect of cascade condenser temperature on COP and exergetic efficiency for (a) ammonia "R717" and (b) carbon dioxide " $\mathrm{R} 744$ " $\left(\mathrm{Ta}=\mathrm{Tc}=35^{\circ} \mathrm{C}, \mathrm{Te} \_\mathrm{vcr}=-40^{\circ} \mathrm{C}, \mathrm{Tg}=84.5^{\circ} \mathrm{C}, \varepsilon \_\right.$she $=0.75, \eta \_$comp $=0.8$, Qe_vcr $=100 \mathrm{~kW}, \mathrm{~A}=0{ }^{\circ} \mathrm{C}, \mathrm{To}=298.15 \mathrm{~K}$ )

Figure 3(a) and (b) show the effect of cascade condenser temperature on COP and exergetic efficiency for ammonia and carbon-dioxide in low temperature circuit. It is observed that both COP and exergetic efficiency reduce with increase in cascade condenser temperature for carbon-dioxide cycle. In ammonia cascade system, the COP first increases, achieves a maximum value at cascade temperature of $4^{\circ} \mathrm{C}$ and then reduces. Also, at different approach $(\mathrm{A}=0,5$ and 10$)$ the maximum $\mathrm{COP}$ occurs at same cascade temperature of $4^{\circ} \mathrm{C}$. It is observed that with increase in approach COP decreases. However, the difference between maximum and minimum values is very small. The carbon-dioxide cycle cascade system has the lower values of COP and exergetic efficiency in comparison to ammonia cycle cascade system. The increase in cascade condenser temperature results in increase in pressure ratio across compressor, increase in mass flow rate in compression circuit and increase in absorber pressure. The first two factors account for increase in compressor power and the last factor i.e. increase in absorber pressure accounts for decrease in strong solution concentration ' $X s$ '. The weak solution concentration ' $X w$ 'remains constant. Thus, the solution circulation ratio (given by $X w /(X w-X s)$ decreases. The reduction in solution circulation ratio reduces the generator heat duty. Thus, COP of the system may increase or decrease depending upon the increase in compressor power requirement and reduction in generator heat duty.

Further the optimum generator temperature corresponding to maximum COP is higher in comparison to optimum generator temperature corresponding to maximum exergetic efficiency. Also, at optimum generator temperature the cascade condenser temperature corresponding to maximum COP is higher in comparison to 
cascade condenser temperature corresponding to maximum exergetic efficiency. So, it could be a tradeoff to choose between maximum COP and maximum exergetic efficiency the appropriate values of temperatures in both the conditions.

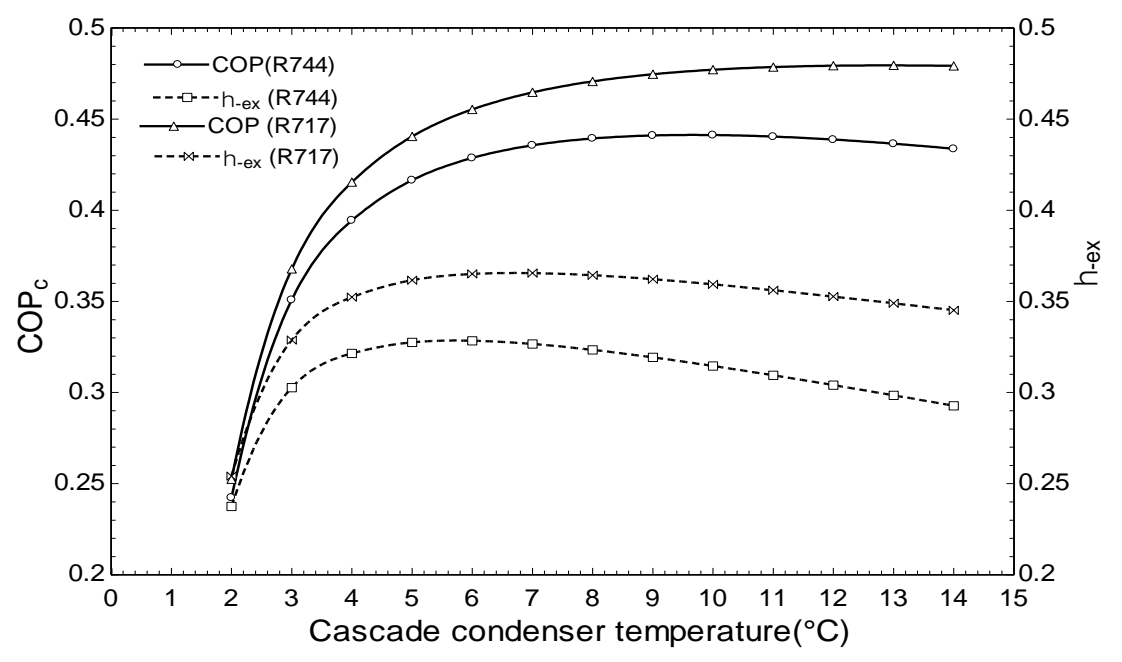

Figure 3(c). Effect of cascade condenser temperature on COP and exergetic efficiency for carbon dioxide "R744" and ammonia "R714" $\left(\mathrm{Ta}=\mathrm{Tc}=40^{\circ} \mathrm{C}, \mathrm{Te} \_\right.$vcr $=-40^{\circ} \mathrm{C}, \mathrm{Tg}=84.5^{\circ} \mathrm{C}, \varepsilon_{\_}$she $=0.75, \eta \_$comp $=0.8$,

$$
\text { Qe_vcr }=100 \mathrm{~kW}, \overline{\mathrm{A}}=0{ }^{\circ} \mathrm{C}, \mathrm{To}=298.15 \mathrm{~K} \text { ) }
$$

Figure 3(c) shows the effect of cascade condenser temperature at (optimum generator temperature) on COP and exergetic efficiency but at higher absorber and condenser temperature which is $40^{\circ} \mathrm{C}$ in this study for both the ammonia and carbon dioxide as refrigerants in low temperature stage. It is observed that with the increase in cascade temperature both the COP and exergetic efficiency increases significantly, reaches to a maximum value and then start to decrease. For ammonia maximum COP and maximum exergetic efficiency occur at $13^{\circ} \mathrm{C}$ and $7^{\circ} \mathrm{C}$ respectively whereas for carbon dioxide maximum COP and maximum exergetic efficiency occur at $9^{\circ} \mathrm{C}$ and $6^{\circ} \mathrm{C}$ respectively.

Figure 4(a) represents the values of maximum COP and maximum exergetic efficiency with variation in cascade condenser temperature for ammonia. The optimum generator temperature for ammonia has also been computed corresponding to both maximum COP and maximum exergetic efficiency. It is observed that the optimum generator temperature decreases with increase in cascade condenser temperature. The optimum generator temperature for maximum COP is higher than optimum generator temperature for maximum exergetic efficiency. Figure 4(b) illustrates the comparison of maximum exergetic efficiencies of ammonia and carbon-dioxide and corresponding optimum generator temperatures. The values of exergetic efficiency are also calculated for generator temperature equal to $84.5^{\circ} \mathrm{C}$. It is observed that if generator temperature is not optimum then exergetic efficiency continues to decrease with increase in cascade condenser temperature. The maximum exergetic efficiency and corresponding generator temperature also decrease with increase in cascade condenser temperature. The maximum exergetic efficiency and optimum generator temperature both are lower for carbon-dioxide cycle cascade system in comparison to ammonia cycle cascade system. The cascade condenser temperature corresponding to the optimum generator temperature is certainly optimum cascade condenser temperature. However the maximum exergetic efficiency is not the global maximum exergetic efficiency rather it is localized maximum value of exergetic efficiency corresponding to given conditions. 


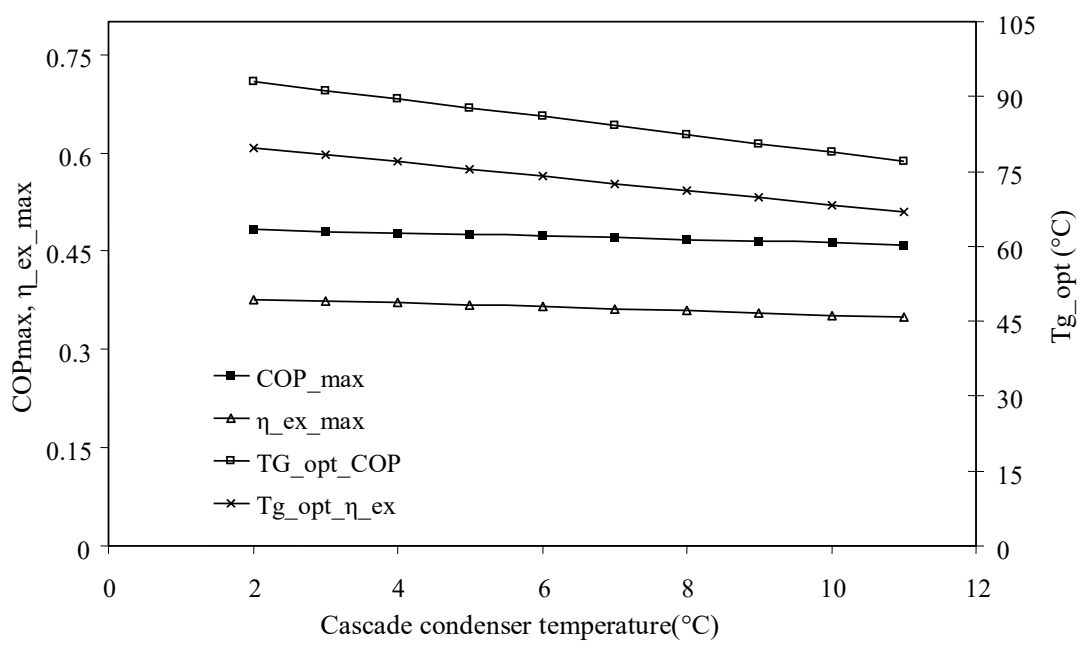

Figure 4(a). COP_max and $\eta \_$ex_max versus cascade condenser temperature and corresponding $T g \_o p t$ for ammonia "R714" $\left(\mathrm{Ta}=\mathrm{Tc}=35^{\circ} \mathrm{C}, \mathrm{Te} \_v c r=-40{ }^{\circ} \mathrm{C}, \varepsilon_{-}\right.$she $=0.75, \eta \_$comp $=0.8$, Qe_ver $=100 \mathrm{~kW}, \mathrm{~A}=0{ }^{\circ} \mathrm{C}$, To $=298.15 \mathrm{~K})$

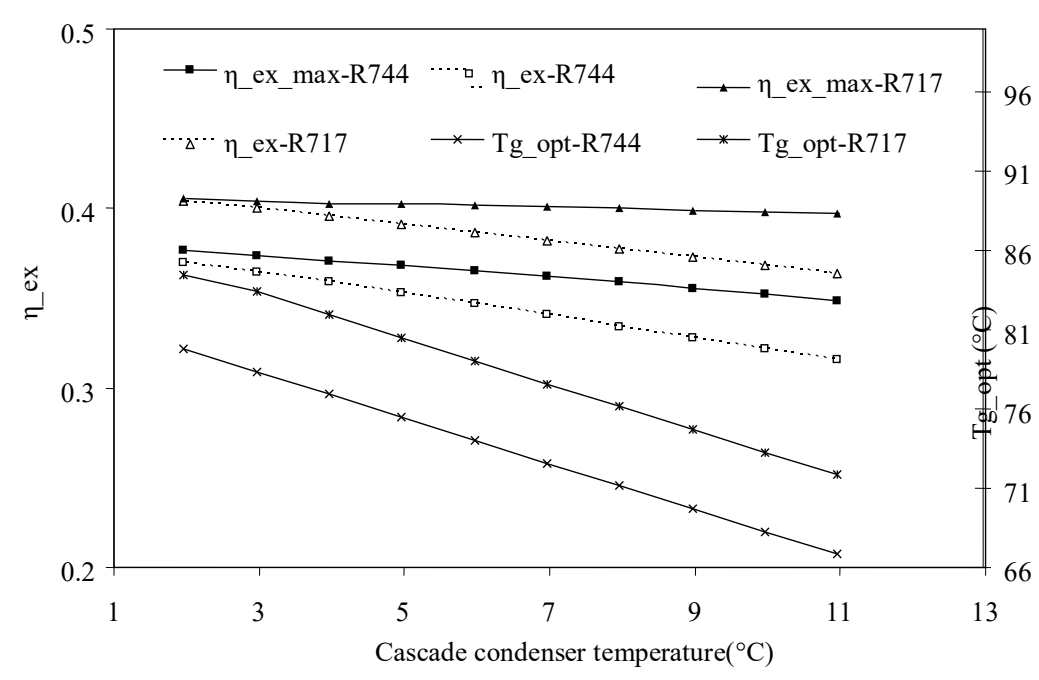

Figure 4(b). Exergetic efficiency versus cascade condenser temperature and $\mathrm{Tg}$ _opt corresponding maximum exergetic efficiency for ammonia "R744" and carbon dioxide "R744" $\left(\mathrm{Ta}=\mathrm{Tc}=35^{\circ} \mathrm{C}, \mathrm{Te} \_\mathrm{vcr}=-40^{\circ} \mathrm{C}\right.$, $\varepsilon_{-}$she $=0.75, \eta \_$comp $=0.8, \mathrm{Qe} \_v c r=100 \mathrm{~kW}, \mathrm{~A}=0{ }^{\circ} \mathrm{C}, \mathrm{To}=298.15 \mathrm{~K}$ )

\section{Effect of Generator Temperature}

Figure 5(a) and (b) illustrate the effect of generator temperature on COP and exergetic efficiency at different absorber temperatures and different evaporator temperatures. It is observed that with increase in generator temperature (for a specific absorber and specific evaporator temperature), COP increases initially, attains a maximum value and with further increase in generator temperature COP decreases marginally. The trend followed by exergetic efficiency curves is similar to trend followed by COP curves with the exception that the fall of exergetic efficiency is significant after it attains maximum value. At particular evaporator and cascade condenser temperatures, the compressor power required for a constant cooling load remains constant. This implies that COP of the low temperature stage is constant. Thus the variation in COP of the cascade system is dependent on variations in $\mathrm{COP}$ of the high temperature i.e. COP of the single effect absorption system. The increase in generator temperature causes the solution circulation ratio to reduce and the heat duty of the generator reduces. The reduction in generator heat duty increases the $\mathrm{COP}$ of the high temperature stage and consequently the $\mathrm{COP}$ of the cascade system increases initially. However with further increase in generator temperature, the temperature difference between generator and sub-cooled solution entering the generator increases. Thus the irreversibility in generator 
increases. The increase in generator temperature also accounts for increase in temperatures of weak solution exiting the generator and the refrigerant exiting the generator.

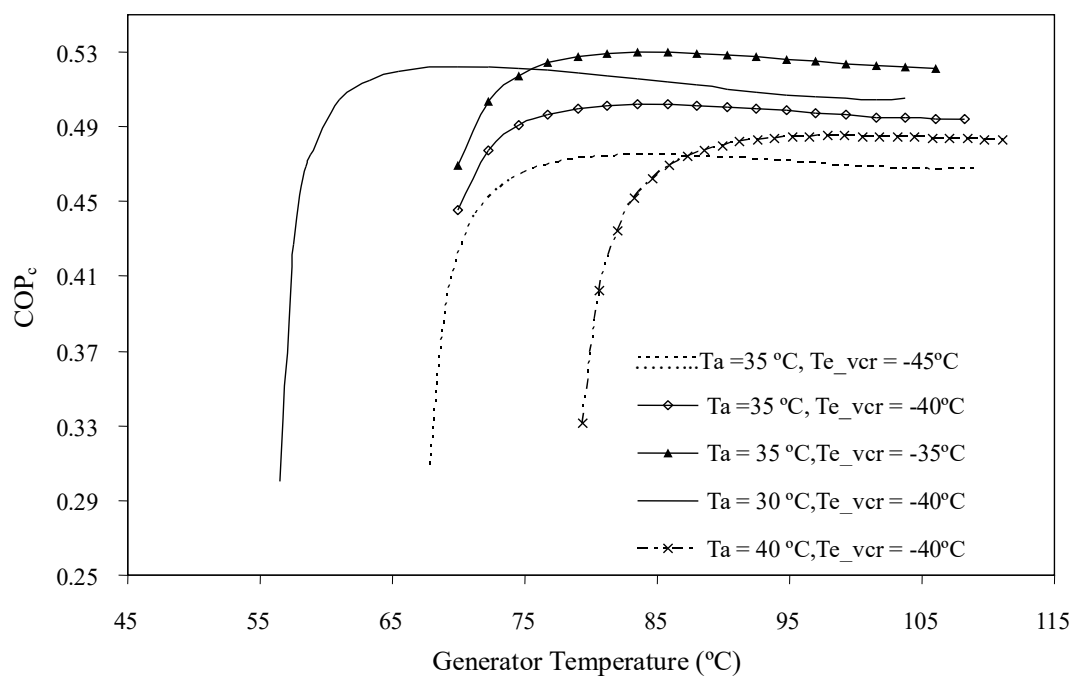

(a)

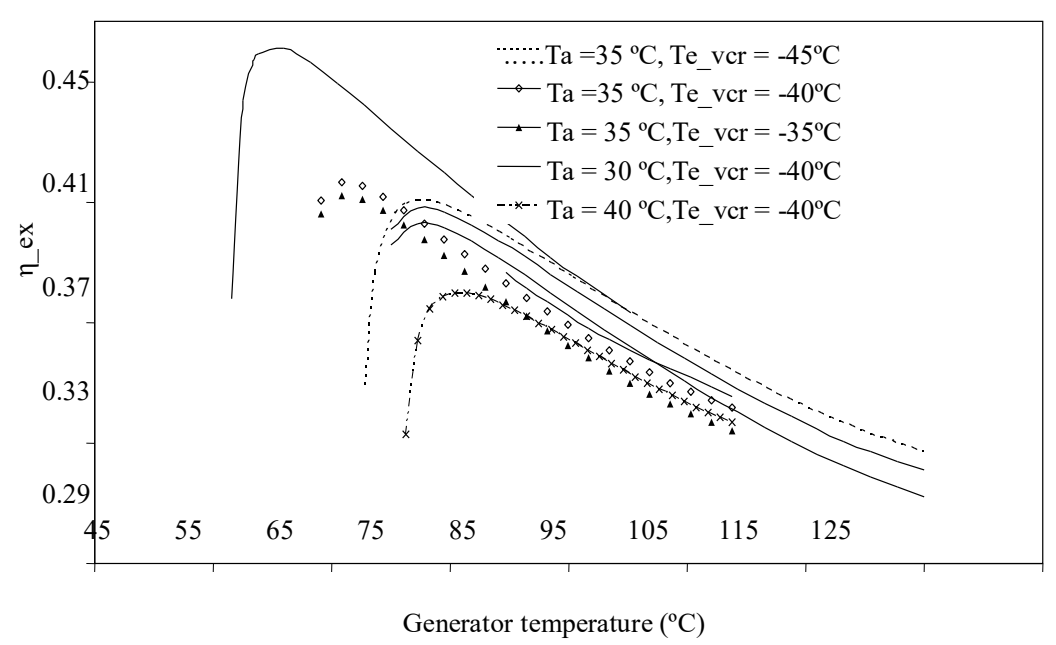

(b)

Figure 5. Effect of generator temperature on (a) COP and (b) exergetic efficiency for range of evaporator and absorber temperatures (Refrigerant ammonia "R714", Ta $=\mathrm{Tc}, \mathrm{Tcc}=7^{\circ} \mathrm{C}$, effectiveness $=0.75$, Qe $\mathrm{vcr}=100$ $\mathrm{kW}$, compressor efficiency $=0.8$, Approach $=0{ }^{\circ} \mathrm{C}$ )

Thus, irreversibility in absorber and condenser increases, hence the positive effect of increase of generator temperature on COP of high temperature stage is counterbalanced by negative effects of increase in irreversibility in generator, absorber and condenser. Hence COP of the cascade system becomes constant and even reduces marginally with increase in generator temperature. The reduction in generator heat duty brings down the exergy input initially due to fall in solution circulation ratio. The exergetic efficiency, therefore, increases and achieves a maximum value. The rate of decrease of solution circulation ratio reduces with further increase in generator temperature and therefore exergy input (given by $\dot{Q}_{g}\left(1-\frac{T_{0}}{T_{g}}\right)+\dot{W}_{p}+\dot{W}_{c_{-} v c r}$ ) increases whereas output exergy (given by $\dot{Q}_{e}\left|\left(1-\frac{T_{0}}{T_{r}}\right)\right|$ ) remains constant and hence the exergetic efficiency drops sharply. The trend of various parameters which constitute input exergy is shown in Figure 7. 


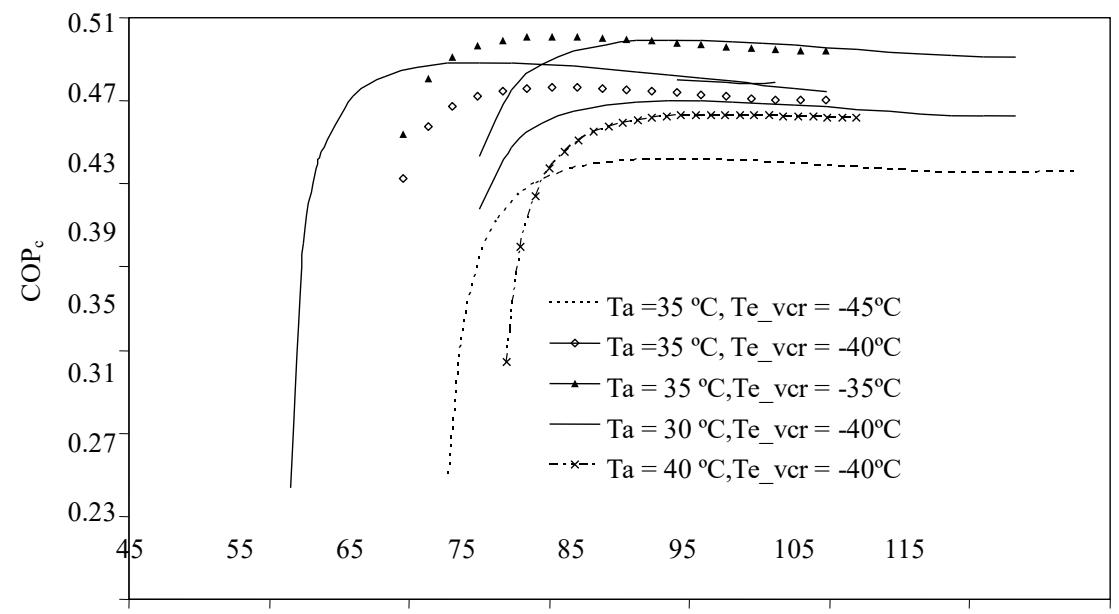

Generator Temperature $\left({ }^{\circ} \mathrm{C}\right)$

(a)

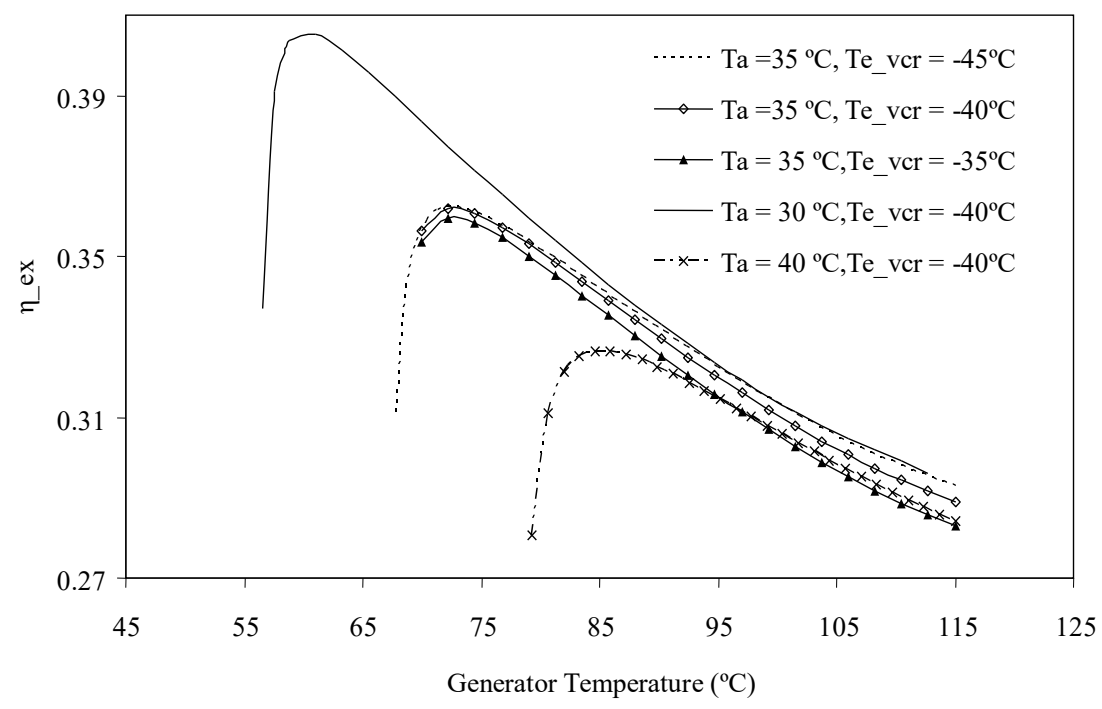

(b)

Figure 6. Effect of generator temperature on (a) $\mathrm{COP}$ and (b) exergetic efficiency for range of evaporator and absorber temperatures (Refrigerant carbon-dioxide "R744", $\mathrm{Ta}=\mathrm{Tc}, \mathrm{Tcc}=7^{\circ} \mathrm{C}$, effectiveness $=0.75$, Qe $\mathrm{vcr}=$ $100 \mathrm{~kW}$, compressor efficiency $=0.8$, Approach $=0{ }^{\circ} \mathrm{C}$ )

Figure 5 (a) and (b) also show that with increase in evaporator temperature the COP increases whereas exergetic efficiency decreases. The COP increases because increase in evaporator temperature reduces the pressure ratio across the compressor and hence the compressor power required reduces which in turn reduces the total input energy required. The exergetic efficiency reduces because of reduction in output exergy. The input exergy required also reduces however the rate of decrease in input exergy is lower in comparison to rate of decrease of output exergy. The Figure 5(a) and (b) also show the effect of absorber temperature on COP and exergetic efficiency. The reduction in absorber temperature accounts for reduction in solution circulation ratio which reduces generator heat duty and increases COP. The reduction in generator heat duty also accounts for reduction in input exergy, it results in increase in exergetic efficiency. Simultaneously, the optimum generator temperature also reduces with reduction in absorber temperature. This indicates that an absorption compression cascade refrigeration system requires lower temperature heat source when absorber temperature is reduced.

Figure 6(a) and (b) illustrate the variation of COP and exergetic efficiency for carbon-dioxide cascade system. The comparison of Figures (5) and (6) illustrates that the COP and exergetic efficiency values for carbon-dioxide cascade cycle are lower in comparison to ammonia cascade cycle. 


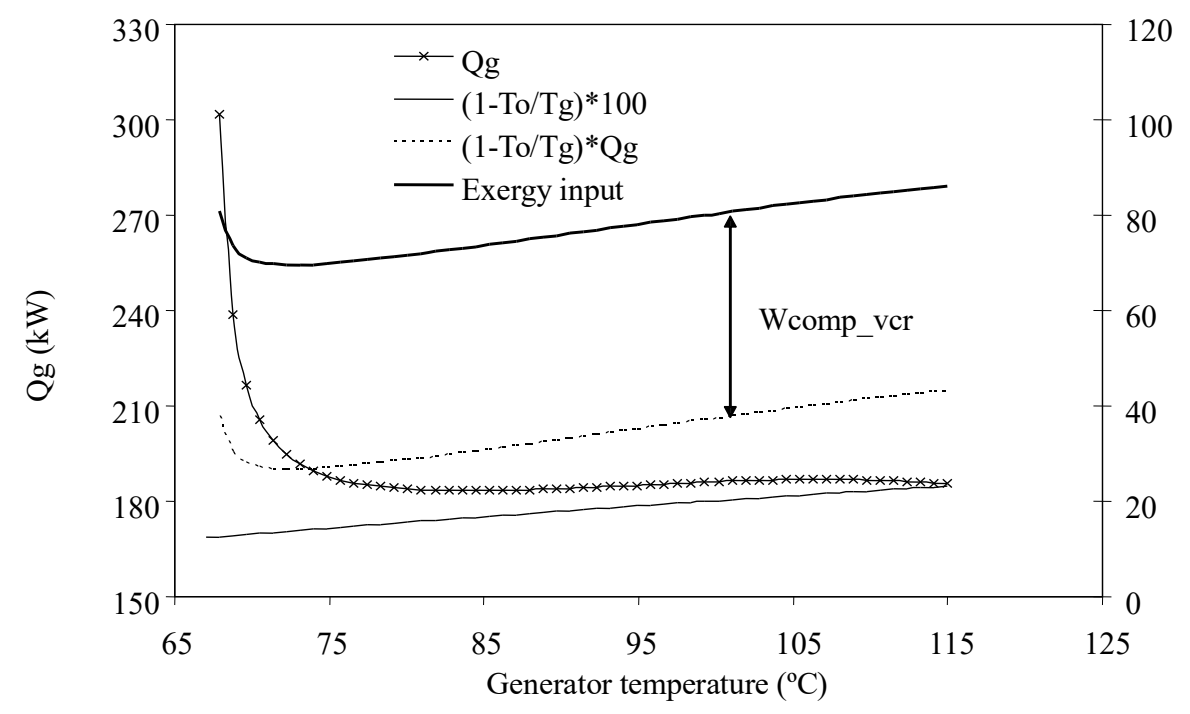

Figure 7. Variation of parameteric factors which constitute input exergy $\left(\mathrm{Ta}=\mathrm{Tc}=35^{\circ} \mathrm{C}, \mathrm{Tcc}=7^{\circ} \mathrm{C}\right.$, effectiveness $=0.75$, Qe_vcr $=100 \mathrm{~kW}$, compressor efficiency $=0.8$, Approach $=0{ }^{\circ} \mathrm{C}$ )

\section{Effect of Effectiveness of Solution Heat Exchanger, Approach in Cascade Condenser and Efficiency of Compressor in Low Temperature Stage}

Figures 8 and 9 show the effect of effectiveness of solution heat exchanger, approach in cascade condenser and efficiency of compressor in low temperature stage on the COP and exergetic efficiency. The reduction in effectiveness of solution heat exchanger is responsible for decrease in COP and exergetic efficiency. The reduction in effectiveness of solution heat exchangers causes the temperature difference to increase between the strong solution exiting the solution heat exchanger and the generator temperature. Thus the heat duty and irreversibility in generator increase. Moreover at lower values of effectiveness of solution heat exchanger, the temperature difference between entering and exiting streams of strong and weak solutions is larger in comparison to when the effectiveness is higher. Thus at lower values of effectiveness, the irreversibility in solution heat exchanger is more. The above factors lead to increase the total exergy destruction in the cycle and the COP and exergetic efficiency reduce.

The increase in approach from $0^{\circ} \mathrm{C}$ to $10^{\circ} \mathrm{C}$ causes the absorber pressure to increase which increases the solution circulation ratio. The increase in solution circulation ratio increases the generator heat duty which brings down the COP. It also increases the irreversibility in generator and cascade condenser. Thus total exergy destruction increases and hence exergetic efficiency reduces.

The increase in isentropic efficiencies of compressor reduces the compressor power required and hence input energy and input exergy reduce thereby increasing the COP and the exergetic efficiency. 


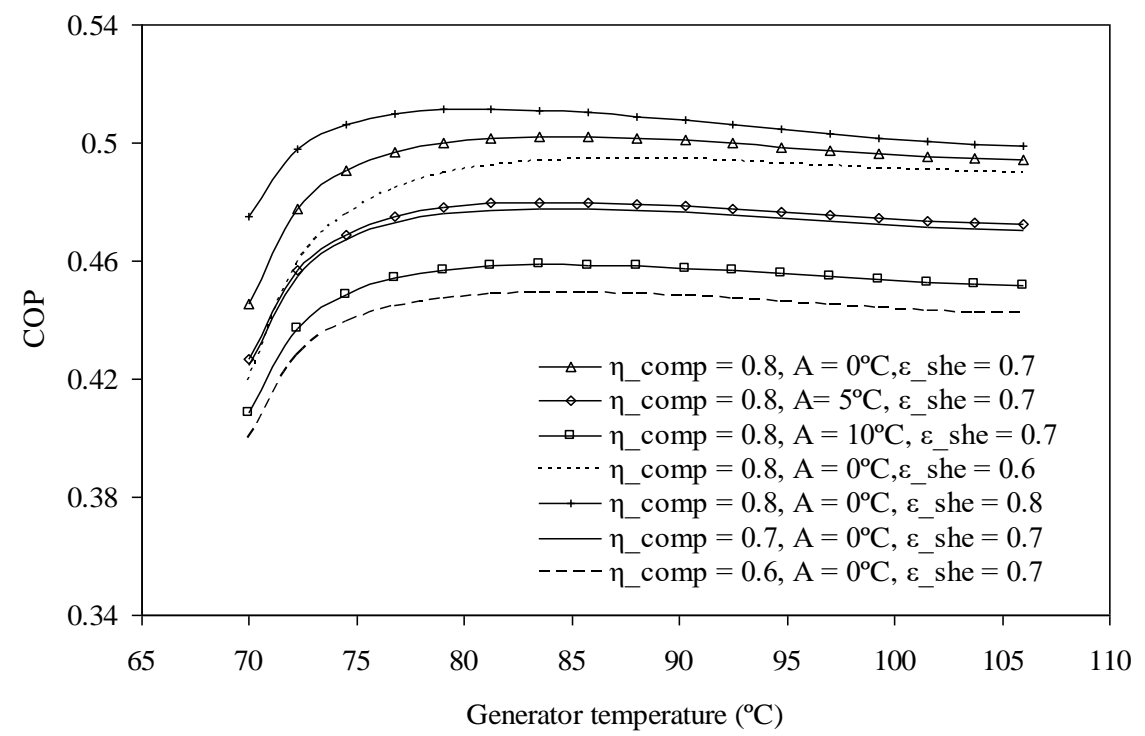

(a)

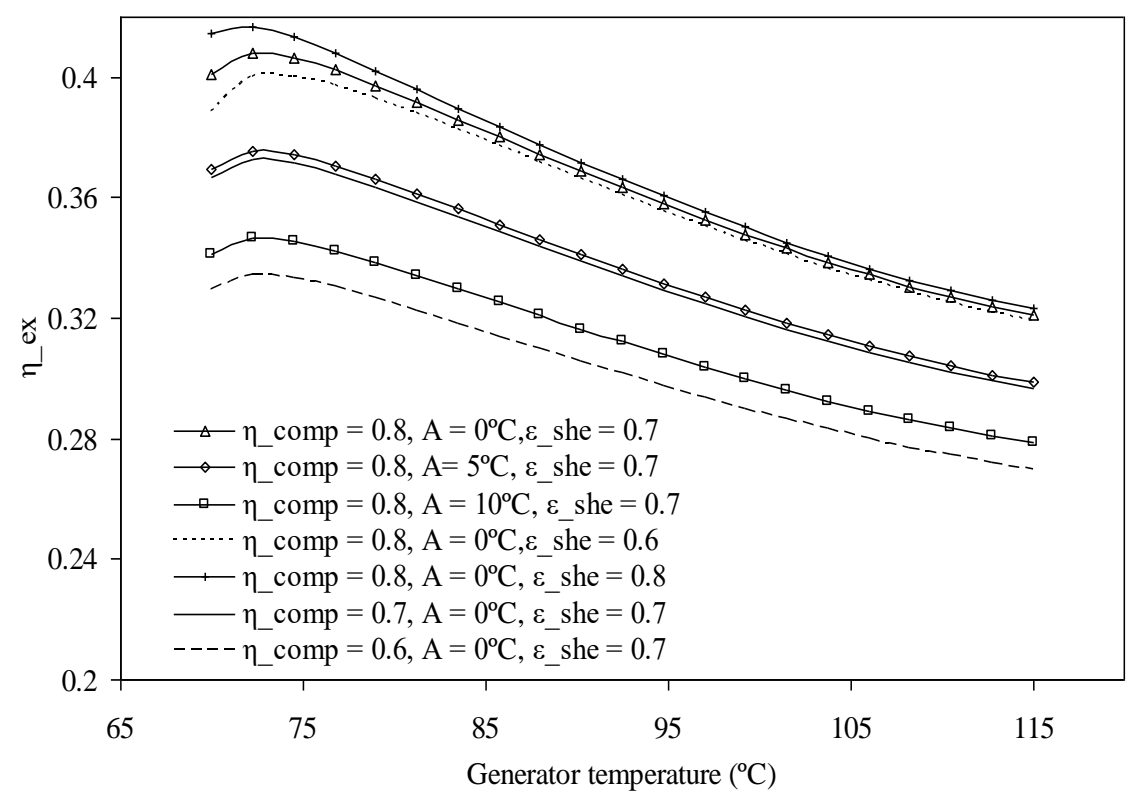

(b)

Figure 8. Effect of generator temperature on (a) $\mathrm{COP}$ and (b) exergetic efficiency for varying approach, effectiveness of 'she' and compressor efficiency (Refrigerant ammonia "R714", $\mathrm{Ta}=\mathrm{Tc}=35^{\circ} \mathrm{C}, \mathrm{Tcc}=7^{\circ} \mathrm{C}$, Te_vcr $=-40^{\circ} \mathrm{C}, \mathrm{Qe} \_$vcr $=100 \mathrm{~kW}$ ) 


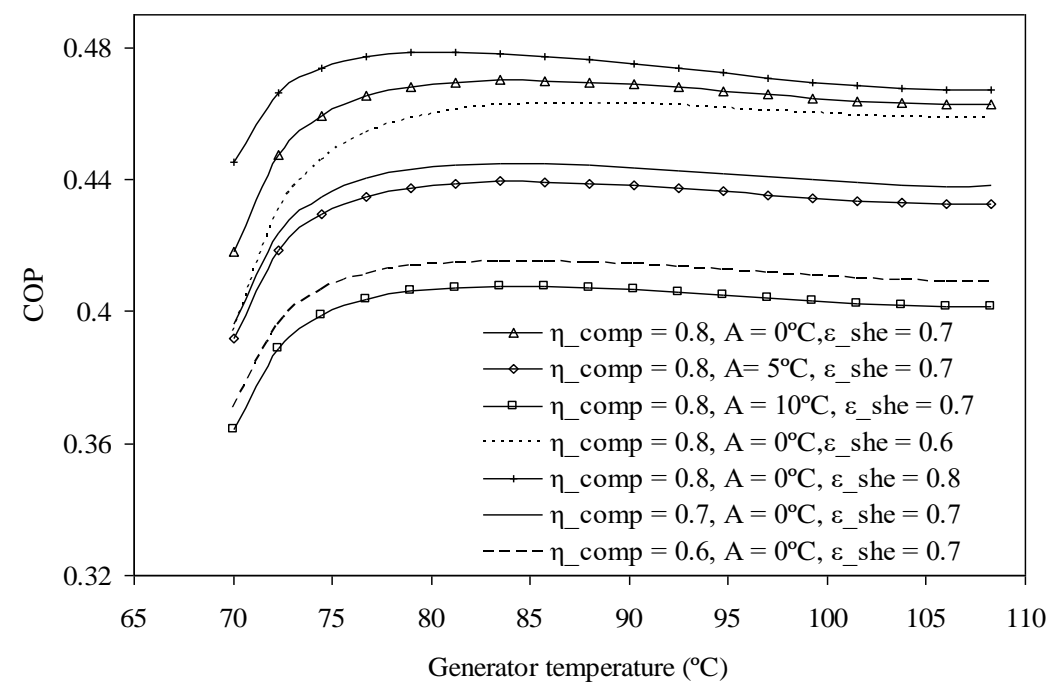

(a)

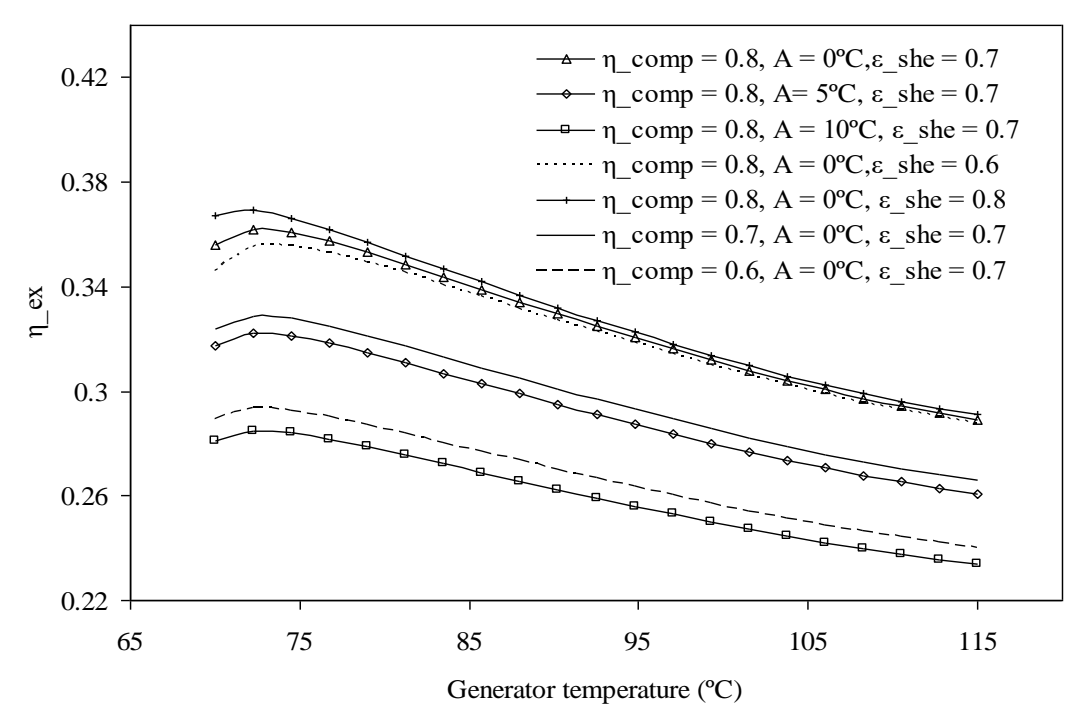

(b)

Figure 9. Effect of generator temperature on (a) $\mathrm{COP}$ and (b) exergetic efficiency for varying approach, effectiveness of 'she' and compressor efficiency (Refrigerant carbon-dioxide "R744", $\mathrm{Ta}=\mathrm{Tc}=35^{\circ} \mathrm{C}, \mathrm{Tcc}=7^{\circ} \mathrm{C}$, Te_vcr $=-40^{\circ} \mathrm{C}, \mathrm{Qe} \_\mathrm{vcr}=100 \mathrm{~kW}$ )

\section{CONCLUSIONS}

In the thermodynamic analysis of a compression absorption cascade refrigeration system, the following conclusions are drawn from it:

The COP and exergetic efficiency reduce with increase in cascade condenser temperature for carbon dioxide as refrigerant in compression system irrespective of approach temperature. The drop in COP is large at higher approach. In case of ammonia as refrigerant in compression system, the COP increases initially with increase in cascade condenser temperature, attains a maximum value and then decreases. However, the difference between maximum and minimum values of COP is very nominal at different approach. The exergetic efficiency decreases with increase in cascade condenser temperature.

- The maximum values of COP and exergetic efficiency occur corresponding to different generator temperatures. The maximum COP occurs at a generator temperature higher than the generator temperature corresponding to maximum exergetic efficiency irrespective of cascade condenser temperature and approach. The optimum generator temperature corresponding to maximum COP and maximum exergetic 
efficiency reduce with increase in cascade condenser temperature. The optimum generator temperature corresponding to maximum COP and maximum exergetic efficiency for carbon dioxide cascade cycle and ammonia cascade cycle is same at similar variables but value of maximum COP and maximum exergetic efficiency of ammonia cascade cycle is higher in comparison to carbon dioxide cascade cycle.

- The COP decreases and exergetic efficiency increases with decrease in evaporator temperature for ammonia cascade cycle. It is significant that with increase in absorber temperature and condenser temperature i.e. at $40^{\circ} \mathrm{C}$, both $\mathrm{COP}$ and exergetic efficiency increases, reaches to a maximum value and then decrease. Moreover, the optimum generator temperatures corresponding to maximum COP and maximum exergetic efficiency are also observed to shift towards higher values. Similar trends occur in case of carbon dioxide cascade cycle also. However the maximum values of COP and exergetic efficiency are lower for carbon dioxide cascade cycle in comparison to ammonia cascade cycle.

- Increase in approach in cascade condenser results in decrease in the COP and exergetic efficiency for both the refrigerants. The increase in effectiveness of solution heat exchanger increases the COP and exergetic efficiency marginally. The COP and exergetic efficiency increases significantly with the increase in isentropic efficiency of compressor.

Finally, it is concluded that VAR cycle of such cascade system can run using heat energy also from industrial waste heat. Thus, saving lots of electrical energy and by incorporating the appropriate parameters heat energy could also be saved. Results also predict that environment friendly refrigerant ammonia is a better refrigerant compared to carbon dioxide for low stage compression system in a compression absorption cascade refrigeration system.

\section{NOMENCLATURE}

A Approach in Cascade condenser

$\mathrm{CO}_{2} \quad$ Carbon dioxide

COP Coefficient of performance (dimensionless)

CRS Compression refrigeration system

ED Exergy destruction $(\mathrm{kW})$

$E D_{\text {total }} \quad$ Total exergy destruction $(\mathrm{kW})$

$E F \quad$ Exergy of fuel $(\mathrm{kW})$

EP $\quad$ Exergy in product $(\mathrm{kW})$

$\mathrm{H}_{2} \mathrm{O} \quad$ Water

HT High temperature

$\mathrm{Li}-\mathrm{Br} \quad$ Lithium bromide

LT Low temperature

$\mathrm{NH}_{3} \quad$ Ammonia

$\mathrm{P} \quad$ Pressure

$\dot{Q} \quad$ heat rate $(\mathrm{kW})$

s $\quad$ Entropy $(\mathrm{kJ} / \mathrm{kgK})$

$\mathrm{T}_{\mathrm{g}} \quad$ Generator temperature (K)

$\mathrm{T}_{0} \quad$ Ambient temperature $(\mathrm{K})$

$\mathrm{T}_{\mathrm{r}} \quad$ Refrigerant temperature $(\mathrm{K})$

VCR Vapor compression refrigeration

VAR Vapor absorption refrigeration

$\dot{W}_{P} \quad$ Pump work (kW)

$\dot{W}_{\text {СOMP }} \quad$ Compressor work $(\mathrm{kW})$

$\mathrm{X} \quad$ Solution Concentration

Xs Strong solution concentration

$\mathrm{Xw} \quad$ Weak solution concentration

\section{GREEK LETTERS}

$\varepsilon_{-}$she Effectiveness of solution heat exchanger

$\eta \_$comp Compressure efficiency 


$$
\eta \_ \text {Ex } \quad \text { Exergetic efficiecy }
$$

\section{Subscripts}

a

c

comp

cc

e

g

rtv_htc Refrigerant thermostatic expansion valve of high temperature circuit

rtv_litc Refrigerant thermostatic expansion valve of low temperature circuit

she Solution heat exchanger

stv Solution thermostatic expansion valve

\section{REFERENCES}

[1] Chakravarthy, V.S., Shah, R.K., Venkatarathnam, G. (2011). A Review of Refrigeration Methods in the Temperature Range 4-300 K, J. Therm. Sci. Eng. Appl., 3, 02081.

[2] Cimsit, C., Ozturk IT. (2012). Analysis of compression-absorption cascade refrigeration cycle, Appl Therm Eng, 40, 311-317.

[3] Reddy, V.S., Kaushik, S.C., Tyagi, S.K. (2014). Exergetic analysis and evaluation of coal-fired supercritical thermal power plant and natural gas-fired combined cycle power Plant, Clean Techn Environ Policy, 16, 489-499. [4] Reddy, V.S., Panwar, N.L., Kaushik, S.C. (2012). Exergetic analysis of a vapour compression refrigeration system with R134a, R143a, R152a, R404A, R407C, R410A, R502 and R507A, Clean Technologies and Environmental Policy, 14(1), 47-53.

[5] Seara, F., Sieres, J., Vazquez, M. (2006). Compression-absorption cascade refrigeration system, Applied Thermal Engineering 26, 502-512.

[6] Riffat, S.B., Shankland, N. (1993). Integration of absorption and vapor-compression systems, Applied Energy, 46(4), 303-316.

[7] Kairouani, L., Nehdi, E. (2006). Cooling performance and energy saving of a compression-absorption refrigeration system assisted by geothermal energy, Appl Therm Eng., 26, 288-94.

[8] Meng, X., Zheng, D., Wang, J., Li, X. (2013). Energy saving mechanism analysis of the absorptioncompression hybrid refrigeration cycle, Renewable Energy, 57, 43-50.

[9] Colorado, D., Velazquez, V.M. (2013). Exergy analysis of a compression-absorption cascade system for refrigeration, Int. J. Energy Res, 37, 1851-65.

[10] Garimella, S., Brown, A.M., Nagavarapu, A.K. (2011). Waste heat driven absorption/vapor-compression cascade refrigeration system for megawatt scale, high-flux, low-temperature cooling, Int. J. Refrig., 34, 17761785 .

[11] Seyfouri, Z., Ameri, M. (2012). Analysis of integrated compression-absorption refrigeration systems powered by a microturbine, International journal of Refrigeration, 35, 1639-1646.

[12] Wang, L., Aihua, M., Yingying, T., Xiaolong, Cui., Hongli, Cui. (2012). Study on Solar-Assisted Cascade Refrigeration System, International Conference on Future Energy, Environment, and Materials. Energy Procedia, $16,1503-1509$.

[13] Chen, Y., Han, W., Sun, L., Jin, H. (2015). A new absorption-compression refrigeration system using a midtemperature heat source for freezing application, The 7th International Conference on Applied Energy - ICAE (2015), Energy Procedia, 75, 560 - 565.

[14] Arora, A., Dixit, M., Kaushik, S.C. (2016). Energy and exergy analysis of a double effect parallel flow $\mathrm{LiBr} / \mathrm{H}_{2} \mathrm{O}$ absorption refrigeration system, Journal of Thermal Engineering, 2(1), 541-549.

[15] Kutlu, Ç., Ünal, Ș., Erdinc, M. T. (2016). Thermodynamic analysis of bi-evaporator ejector refrigeration cycle using R744 as natural refrigerant, Journal of Thermal Engineering, 2(2), 735-740.

[16] Dixit, M., Arora, A., Kaushik, S. C. (2016). Energy and exergy analysis of a waste heat driven cycle for triple effect refrigeration, Journal of Thermal Engineering, 2(5), 954-961.

[17] Arora, A., Dixit, M., Kaushik, S.C. (2016). Computation of optimum parameters of a half effect water-lithium bromide vapour absorption refrigeration system", Journal of Thermal Engineering, 2(2), 683-692. 
[18] Jain, V., Sachdeva, G., Kachhwaha, S.S. (2013). NLP model based thermo-economic optimization of vapour compression-absorption cascaded refrigeration system, Energy Conversion and Management, 93, 49-62.

[19] Jain, V., Kachhwaha, S.S., Sachdeva, G. (2013). Thermodynamic performance analysis of a vapour compression-absorption cascaded refrigeration system, Energy Conversion and Management, 75, 685-700.

[20] Jain, V., Sachdeva, G., Kachhwaha, S.S., Patel, B. (2016). Thermo-economic and environmental analyses based multi-objective optimization of vapor compression-absorption cascaded refrigeration system using NSGAII technique, Energy Conversion and Management, 113, 230-242.

[21] Dixit, M., Kaushik, S.C., Arora, A. (2015). Energy and exergy analysis of absorption-compression cascade refrigeration system, Journal of Thermal Engineering, 1(1), 1-12.

[22] Kaushik, S.C., Arora, A., Bilga P. S. (2016). Alternatives in Refrigeration and Air Conditioning, I.K. International House Publishing, $1 / \mathrm{e}$, India.

[23] Megdouli, K., Tashtoush, B.M., Nahdi, E., Elankhdar, M., Mhimid, A., Kairouani, L. (2017). Performance analysis of a combined vapor compression cycle and ejector cycle for refrigeration cogeneration, International journal of refrigeration, 74, 517-527.

[24] Patel, B., Desai, N.B., Kachhwaha, S.S. (2017). Thermo-economic analysis of solar-biomass organic Rankine cycle powered cascaded vapor compression-absorption system, Solar energy, 157, 920-933.

[25] Chen, Y., Han, W., Jin, H. (2017). Proposal and analysis of a novel heat driven absorption-compression refrigeration system at low temperatures, Applied Energy, 185, 2106-2116.

[26] Yingjie, Xu., Jiang, N., Qin Wang, Q., Han, X., Gao, Z., Chen, G. (2017). Proposal and thermodynamic analysis of an ejection-compression refrigeration cycle driven by low-grade heat, Energy Conversion and Management, 145, 343-352.

[27] Yingjie, Xu., Jiang, N., Pan, F., Wang, Q., Gao, Z., Chen, G. (2017). Comparative study on two low-grade heat driven absorption-compression refrigeration cycles based on energy, exergy, economic and environmental (4E) analyses, Energy Conversion and Management, 133, 535-347.

[28] Klein, S.A., Alvarado, F. (2005). Engineering Equation Solver Version 7.441, F-Chart software Middleton: WI.

[29] Pa.'tek, J., Klomfar, J. (2006). A computationally effective formulation of the thermodynamic properties of water-lithium bromide solutions from $273 \mathrm{~K}$ to $500 \mathrm{~K}$ over full composition range, International Journal of Refrigeration, 29, 566-578. 